\title{
El legado científico del exilio español en México a través de Ciencia. Revista Hispano- americana de ciencias puras y aplicadas
}

The scientific legacy of the Spanish exile in México through Ciencia: Revista Hispano-americana de ciencias puras y aplicadas

\begin{abstract}
María Guadalupe LANDA LANDA (1), Angélica Briones Huerta (1) y Apolinar SÁnchez Hernández (2)
Departamento de Publicaciones Periódicas. UNAM-DGB Edificio de "Biblioteca Central" Circuito Interior s/n, Ciudad Universitaria, Deleg. Coyoacán C.P. 04510, México, D.F. guadalupe_landa@dgb.unam.mx, revistas@dgb.unam.mx (2) Departamento de Catálogo Colectivo de Publicaciones Periódicas. UNAM-

DGB, Edificio de "Biblioteca Central", asanchez@dgb.unam.mx / sanherap@gmail.com
\end{abstract}

\section{Resumen}

Este trabajo pretende efectuar una revisión hemerográfica del aporte de los exiliados españoles en México a través del conocimiento científico y de divulgación de "Ciencia. Revista Hispanoamericana de ciencias puras y aplicadas" (1940-1975), publicación fundada por científicos españoles exiliados que se editaba en México. Esta revista tuvo apoyo del gobierno de Lázaro Cárdenas, se le considera una fuente de información y de difusión científica indispensable entre los científicos o investigadores exiliados en toda Hispanoamérica. Sin olvidar que fue una gran impulsora para la creación y desarrollo de otras publicaciones científicas e instituciones presentes hoy en México.

Palabras clave: Revistas científicas. México. Exilio español. Ciencia Hispanoamericana.

\section{Introducción}

Hemos aprendido a volar como los pájaros y a nadar como los peces, pero no hemos aprendido el sencillo arte de vivir juntos como hermanos. Martin Luther King (1)

A lo largo de la historia el hombre ha demostrado sus más terribles y nobles conductas, por ejemplo los conflictos bélicos y la protección al desterrado. Tal es el caso de la visión de futuro que tuvo el general Lázaro Cárdenas del Río, que lo coloca como un extraordinario diplomático y político, al permitir la entrada a México de miles de refugiados españoles.

El conflicto armado en el país ibérico se inició en 1936 pero se originó desde principios del siglo XX. Años de cambios y retrocesos llevaron a España a transitar de la monarquía a la República, mediante el voto, y de la República a la

\begin{abstract}
A hemerographic review of the contribution of the Spanish exile in Mexico is done by analyzing the magazine "Ciencia. Revista Hispanoamericana de ciencias puras y aplicadas" (1940-1975), a publication founded by exiled Spanish scientists and published in Mexico. This magazine had the support of the government of Lázaro Cardenas, and was considered an indispensable scientific channel among the exiled scientists and researchers in all Hispano-America. The journal had also a pioneering role for other Mexican scientific publications.
\end{abstract}

Keywords: Scientific journals. Mexico. Spanish exile. Hispano-American science.

dictadura, a través de las armas. El apoyo de México a España se expresó de las formas más variadas, todas ellas paralelas y continuas. Primero con la ayuda directa que recibió el gobierno republicano, al obtener del mexicano armas, dinero, medicinas y alimentos; segundo, con el apoyo sincero y claro de nuestros diplomáticos, que expresaron en foros y conferencias su repudio a la política internacional de no Intervención (2) y a las invasiones nazi-fascistas; tercero, con la (3) protección a los españoles en legaciones de México en España y Francia (tratado en el acápite anterior); y por último, con el asilo en tierras mexicanas de quinientos niños españoles, de científicos e intelectuales y de los miles de republicanos venidos a México, en cuyo gobierno y pueblo encontraron las puertas abiertas de una nación hermana. 


\section{El exilio español}

En 1938, testigo de la situación en España, Daniel Cosío Villegas, embajador de México en Portugal, y quien había vivido en aquél país, respondió con gratitud al trato que España le había dado, y le propuso al presidente Lázaro Cárdenas un proyecto llamado Operación Inteligencia, para salvaguardar el conocimiento republicano español. El proyecto consistía en invitar a un grupo de intelectuales españoles a que vinieran a México a dar conferencias en las universidades públicas, a cambio de su protección mientras concluía la guerra civil. El mismo Cosío se encargó de elaborar la lista de los posibles invitados, que con ayuda de sus amigos Gabriela Mistral y Alfonso Reyes y de informes solicitados al Instituto de Cooperación Intelectual de París y a la Junta de Cultura Española, realizó entre enero y julio de 1937 (4).

Considerando sus razones personales, se estudió la propuesta de Cosío por el presidente Cárdenas y su equipo, acordando ponerla en práctica. Dicho plan finalmente quedó a cargo del propio Cosío y del subsecretario de Educación Pública, Wenceslao Roces. Se trataba de transportar a 50 intelectuales y científicos españoles a México, dónde les esperaría una institución que les daría alojamiento y las herramientas necesarias para transmitir su conocimiento a otros intelectuales y científicos mexicanos.

Los primeros huéspedes fueron Juan Ramón Jiménez, Juan de la Encina, Enrique Díez Canedo, Gonzalo R. Labora, José Moreno Villa, Adolfo Salazar, Jesús Bal y Gay, Dámaso Alonso y Ramón Menéndez Pidal. A éstos se unieron pronto Pedro Carrasco, León Felipe, Manuel Márquez, Agustín Millares, Manuel Pedroso, Joaquín Xirau, Antonio Medinaveitia, Ramón Iglesias, Álvaro de Albornoz, José Medina Echavarría, Juan Roura Parella, María Zambrano, Joseph Carner y José Gaos, además de Luis Recaséns Fiches, José Moreno Villa y León Felipe, que ya estaban en México al llegar los primeros refugiados (5).

Para estos intelectuales se creó la Casa de España que, desde su nacimiento, fue un espacio cuyo propósito fue vincular a los científicos e intelectuales que llegaban de España a México, conectándolos a través de los cursos especiales y las conferencias que ésta misma organizaba. Contrario al plan original, los profesores no estuvieron en México sólo durante el conflicto, pues su regreso a España, tras la derrota republicana, ponía en peligro su vida. La actividad de la Casa se extendió, pues de los cursos y conferencias se pasó a la publicación de revistas como la Nueva Revista de Filología Hispáni- ca, Foro Internacional e Historia Mexicana, a la organización de cursos itinerantes dictados por profesores españoles y además a la concesión de becas para estancias en el extranjero o para ayudar a los jóvenes investigadores mexicanos a seguir sus pesquisas bajo la dirección de los maestros de la Casa. "[...] El primero en gozar de esta oportunidad fue el famoso filósofo de la identidad mexicana Leopoldo Zea, discípulo predilecto de José Gaos." (Llera Esteban, 2005).

En marzo de 1939, con 35 profesores más y una actividad constante, el presidente Lázaro Cárdenas decidió nombrar a Alfonso Reyes presidente de La Casa de España y de su Patronato. El Patronato se integró con Eduardo Villaseñor, subsecretario de Hacienda, en representación del gobierno; Gustavo Baz, rector de la UNAM; Enrique Arreguín, en nombre de la Secretaría de Educación Pública, y Daniel Cosío Villegas, como secretario del Patronato y de la Casa (Ojeda Revah, 2004).

Consciente de que Franco sería difícilmente derrocado, el gobierno mexicano decidió transformar la Casa de España en una institución permanente: El Colegio de México. Es así, que a partir del 8 de octubre de 1940, la Casa de España dejó de ser un refugio temporal y se convirtió en una institución académica de educación superior, que realiza investigaciones en campos de las ciencias sociales y humanidades, edita libros y revistas, y colabora con otras instituciones nacionales y extranjeras.

Los que participaron en la Casa de España y posteriormente aquellos que se integraron al Colegio de México representan sólo un pequeño porcentaje de los miles de hombres y mujeres españoles que habrían de llegar a nuestro país.

Los frutos del trabajo conjunto para el rescate de españoles fueron casi inmediatos, pues varios fueron los pequeños grupos de personajes que arribaron a México durante los meses de abril y mayo 1938. Primero llegaron barcos con decenas y algunos hasta con centenas de españoles. A principios de abril llegó a México el vapor Siboney con 100 personas, luego llegó el Orizaba con 13 personas, a este le siguió el Flandre, quien arribó a México el 20 de abril, con 39 refugiados españoles y sus familiares, haciendo un total de 77 personas; luego siguieron el Orinoco con 41 personas, el Leerdan con 18, el Monterrey con 6 y el Iberia con 42 españoles más. Sin embargo, no fue hasta la llegada del Sinaia, que finalmente comenzaron una serie de verdaderas expediciones masivas de barcos cargados de refugiados y, con ello, la ayuda generalizada del asilo territorial en México (Pla Brugat, 1999a). 
De acuerdo con este autor, la primera y más famosa de las expediciones masivas fue la del buque francés Sinaia, que había partido del puerto de Sète, con 1599 pasajeros españoles, el 26 de mayo de 1939, y que, tras 18 días de navegación sin incidentes, atracó en tierras mexicanas el 13 de junio de 1939. A su llegada al puerto de Veracruz, recibieron a los pasajeros García Téllez, secretario de Gobernación, Gómez Maganda, gobernador del estado de Veracruz y Juan Negrín, representante del Servicio de Evacuación a los Republicanos españoles (SERE), que en compañía de miles de veracruzanos les dieron fraternal bienvenida. Claudi Esteva Fabregat, que llegó en el Sinaia, recuerda (Pla Brugat, 1999b).:

cuando llegamos, para nosotros fue un día de felicidad suprema. Me acuerdo que había una gran cantidad de jarochos [...] esperándonos en el puerto, que había unas autoridades, pero especialmente para nosotros fue importante el recibimiento sindical, fue un recibimiento popular [...]. Y nosotros no sabíamos prácticamente nada de México, lo que sí sabíamos era de la hostilidad de la Colonia española, del antiguo presidente respecto de nosotros. Entonces ésta, para nosotros, era nuestra gente, éste era nuestro pueblo, y fuimos con ellos [...]. Quizá nos veían como aquel español que nunca habían tratado, ellos habían tratado una España, digamos, histórica, una España de conquista, una España de vencedores, y ahora recibían ellos una España de derrotados, o sea de vencidos. Pero de vencidos también por aquellas mismas personas que quizás históricamente representaban para ellos aquellos que también les habian vencido a ellos.

A los refugiados que llegaron en esa expedición le seguirían, poco tiempo después, el Ipanema con 994 pasajeros, y el Mexique con 2067 españoles a bordo. Antes de finalizar el año llegarían otras tres expediciones a México: dos en el Nyasa con alrededor de 1500 españoles y una en el Santo Domingo con 513 pasajeros, lo que sumó algo más de cinco mil republicanos españoles asilados por México. Para ellos la llegada a México (Maldonado, 1982)

[...] era la culminación de muchas horas de angustia y de incertidumbre, y la certeza, al fin, de una situación estable tras las [sic] azarosos días que marco el signo de la derrota. Quedaban atrás las privaciones de los campos de concentración y la amenaza constante de deportaciones en la Francia ocupada...

Es cierto que la guerra civil española fue cruenta, pero, además de salvar la vida de miles de españoles, también se tuvo la visión de acoger a científicos e intelectuales que contribuyeron a la formación del México contemporáneo, como fue el caso del médico Salvador Zubirán, que se encargó en 1939 de establecer contacto con los mejores científicos de la época. En el trabajo de investigación de Ordóñez Alonso (2000), refiere que en el "Archivo del Comité Técnico de Ayuda a los Republicanos Españoles (CTARE) se localizan 325 científicos refugiados".

Los médicos, conforme indica, fueron los científicos refugiados más numerosos. Sin embargo, muchos no contaban con un título o documentos que los acreditarán como profesionistas. El segundo grupo fue de los ingenieros de diversas especialidades. Los farmacéuticos, arquitectos, químicos, y en menor porcentaje los profesionistas en ciencias exactas y ciencias naturales, integraron el tercer grupo de científicos rescatados (Ordóñez Alonso, 2000).

Estos científicos se incorporaron a las instituciones que en el sexenio de Lázaro Cárdenas se habían creado con nuevos centros de investigación y estudio, como el Instituto Politécnico Nacional, Instituto Nacional de Antropología e Historia y El Colegio de México. Dentro de la Universidad Nacional, tienen un papel importante en la Facultad de Ciencias fundada en 1938, en el Instituto de Derecho Comparado creado en 1940, que posteriormente cambió su nombre a Instituto de Investigaciones Jurídicas; y en 1941 se estableció el Laboratorio de Estudios Médicos y Biológicos, hoy Instituto de Biomédicas (León Portilla, 1987).

Los médicos del exilio fueron un ejemplo de integración: desde el primer momento trabajaron conjuntamente con sus colegas mexicanos. Desempeñaron funciones importantes en el Instituto Nacional de Cardiología, en el Laboratorio de Estudios Médicos y Biológicos de la UNAM, además de incorporarse como docentes a la Facultad de Medicina.

Otra actividad que desarrollaron los refugiados fue la edición de revistas especializadas. En 1939, Lucio Mendieta y Núnez publica la Revista Mexicana de Sociología, colaborando en ella cinco distinguidos españoles: José Gaos, José Miranda, José Medina Echevarría, Luis Recaséns Siches y Juan Roura Parella. La revista Diánoia, fundada por Eduardo Nicol y Eduardo García Máynez. El Boletín de Derecho Comparado del joven jurista Joaquín Rodríguez y Rodríguez. La revista España Peregrina (1940), que se transformó en Cuadernos Americanos, fundada en 1942, representó en su momento la respuesta de intelectuales mexicanos y españoles antifascistas a las circunstancias de la Segunda Guerra Mundial. Esta revista dio lugar a una de las empresas culturales más importante de América Latina. Otras revistas de y para españoles, fueron: Romance (1940-1941), El pasajero (1943), Las Españas (1946-1956), Los 
cuatro gatos (1948-1952), Diálogos de las Españas (1957-1965), Ultramar (1947), y Nuestro Tiempo (1943-1953), entre otras. Las publicaciones fueron un esfuerzo para mantener viva la cultura española, y servir como un vehículo unificador entre los exiliados y sus colegas en América (Mora, Pablo y Ángel Miquel, 2008).

De tal forma, las revistas se convirtieron en un medio, no en un fin: respondieron a la necesidad de expresar los conocimientos e inquietudes de sus creadores. Así surgió una de las revistas científicas más importante en el ámbito hispanoparlante: Ciencia: Revista hispanoamericana de ciencias puras y aplicadas. Su creador fue Ignacio Bolívar Urrutía, que con sus noventa años a cuestas, tuvo ánimo de dirigir la revista. Bolívar manifestó haber venido a México "a morir con dignidad" (Rius, 1987).

La revista es considerada un acontecimiento de gran valor, ya que significa el preámbulo para lo que habría de ser una de las principales actividades del sector intelectual del exilio republicano en el país, la ciencia. Por ello, en el siguiente apartado se tocarán algunas generalidades de la revista científica.

\section{La revista científica}

La trascendencia de las revistas científicas, no ha desaparecido. Prevalece su uso casi universal de comunicación entre los científicos, así como del resto de la sociedad. Cumplen la función más eminente de constituir el mecanismo principal por el cual el científico pretende introducir y establecer el conocimiento derivado de su trabajo en la memoria humana.

Cetto (1995) comenta al respecto sobre su importancia:

Las publicaciones pueden desempeñar un papel fundamental, por múltiples razones: como vehículos de transmisión del conocimiento y recursos esenciales para la enseñanza, y como medios de comunicación de los nuevos hallazgos; para la divulgación de las ciencias, de su historia, sus ideas y sus avances; para la promoción del desarrollo científico; como indicador de la ciencia que producimos, y como medio de definición y difusión del vocabulario científico.

Parte integrante de la ciencia lo constituyen las revistas científicas. A éstas, se les puede examinar desde tres importantes aspectos: el de la comunicación, el de almacenamiento y el social. La revista en cuanto al de la comunicación se presenta en cuatro sentidos: estimular la investigación, beneficiar el flujo de información, establecer prioridades tan rápido como sea posible e informar en partes sucesivas los resultados de un programa de investigación (Meadows, 1974).
Dos componentes son esenciales para los lectores sobre la confiabilidad de lo que leen, esto es: conocimiento de lo que la investigación va dando a conocer, así como la calidad de lo que se presenta.

Las revistas científicas han constituido, y siguen constituyendo todavía, la principal fuente de información de que se valen los científicos de todo el mundo (Perez Alvarez, 1988).

En resumen, puede decirse que la revista cumple con la función de ser el registro permanente de los resultados de una investigación, para conformar un acervo de los avances logrados en las diversas áreas del conocimiento humano, que permitan al investigador y a los interesados en el campo científico comparar trabajos, identificar y ubicar problemas aún no resueltos, desarrollar nuevos proyectos, y actualizarse con respecto a áreas de interés o afines.

"Asimismo, tenemos la firme convicción de que cualquier comunidad científica sana y productiva requiere de medios confiables para acceder a la literatura científica y para publicar los resultados de sus investigaciones de manera oportuna y eficiente." Badran (1995).

\section{Ciencia: Revista hispano-americana de ciencias puras y aplicadas}

Sobre la revista Ciencia, como lo indican Benavent, uno de sus ideales fue demostrar la fortaleza de la colectividad española exiliada, mediante la publicación de artículos científicos y la creación de grupos de trabajo, que mantuvieran viva la esperanza de los republicanos, frente a una España debilitada, que había quedado privada de sus principales figuras intelectuales. Ciencia fue creada dentro de este ámbito, publicándose en México de 1940 a 1975, sus fundadores fueron Ignacio Bolívar Urrutia, entomólogo que había creado el Museo de Historia Natural de Madrid, el hijo de éste, el también entomólogo Ignacio Bolívar y Pieltain y el bioquímico Francisco Giral.

La intención de los fundadores fue crear una estrecha correspondencia entre los científicos españoles exiliados en México y en otros países de América Latina, y de otras latitudes con los intelectuales procedentes de éstos países, así como lograr la colaboración de científicos europeos y norteamericanos con los editores de la revista, que mantenían una relación de simpatía.

Al respecto cabe citar a Ignacio Bolívar, que en una carta dirigida a Indalecio Prieto, la cual es reproducida por Alfredo Baratas, comentaba sobre la revista Ciencia que: 
Convenía demostrar a ojos del Mundo, y especialmente de los científicos americanos, que la Ciencia española no había desaparecido, ni se había sometido a los designios de los dictadores, y como, en su mayor parte, hubo de abandonar la Península y se hallaba acogida entre sus colegas europeos y americanos. Por ello surgió la revista Ciencia.

Continuando con Ciencia, esta logra fortalecerse, a lo largo de su trayectoria, en un referente de primer orden de la producción científica en lengua castellana. Tal aseveración es indicativo del valor que le daban los científicos de la región a sus trabajos científicos, y en la trascendencia que lograba fuera del contexto de América Latina.

Es un hecho que la visibilidad que tuvo la revista Ciencia a nivel internacional fue contundente. Allá por los sesenta, cuando el Institute for Scientific Information (ISI) comenzaba a reproducir las tablas de contenidos de las principales revistas científicas del mundo en su producto Current Contents, distinguió a Ciencia dentro de la primera selección de más de un millar de revistas internacionales, que para ese entonces se situaban a solo siete revistas en idioma español editadas en cuatro países de habla española; Ciencia era una de ella, que se editaba en México.

Para muchos científicos Iberoamericanos Ciencia fue el esfuerzo más serio por crear una revista del tipo de revista Science en español. Para muchos es considerada la mejor revista científica en castellano de la historia, que permaneció viva hasta la muerte de Franco. La importancia es tal, que de su consejo de redacción emergieron dos premios Nobel: el fisiólogo argentino Bernardo Houssay y el español Severo Ochoa, que en ambos casos soportaron la inopia de las dictaduras.

Con este marco, la revista Ciencia, tuvo gran repercusión en la ciencia mexicana. Ante ello, en este trabajo se pretendió realizar una revisión breve del estado actual de las colecciones hemerográficas de este título en México, ya que son un referente histórico y el preámbulo de nuestra historia en el quehacer científico del país. Esta revisión se aproximo a las colecciones más completas con las que cuenta la Universidad Nacional Autónoma de México, descubriendo que existen tres dependencias de esta Universidad, como es el caso de la Facultad de Química, el Instituto de Geofísica y el Universum que ostentan este honor, así como otras más, que tiene pocos números faltantes como son los casos de: La Biblioteca Central, la Facultad de Medicina Veterinaria, el Centro de Investigación en Energía, el Instituto de Biología, el Instituto de Geología y el Instituto de In- vestigaciones en Materiales. De igual manera, existen otras colecciones hemerográficas sobre la revista que se encuentran fuera del ámbito de la UNAM como son los casos de la Universidad Autónoma Metropolitana Campus Azcapotzalco y Xochimilco y el Instituto de Ecología de Xalapa.

Es indudable que la presencia de Ciencia: Revista hispano-americana de ciencias puras y aplicadas, dentro de las bibliotecas mexicanas está presente como patrimonio documental que se resguarda en los acervos de las bibliotecas de la UNAM.

Prueba de la importancia que cobra la memoria científica, es la digitalización de Ciencia, en la que los españoles podrán acceder a la revista setenta años después de iniciar su publicación. Ya que al parecer en España no existía ninguna colección completa, sin embargo la familia de Ignacio Bolívar donó una colección que es albergada en la biblioteca de la Residencia de Estudiantes en Madrid.

\section{Consideraciones finales}

México reconoce la transmisión generosa de personas que tuvieron la capacidad de entregar sus conocimientos y su vocación a las instituciones que les dieron cabida para aportar en la ciencia, la cultura y en el pensamiento universal. El exilio español trajo a nuestro país y a sus instituciones, hombres y mujeres que entregaron su vida y sus conocimientos desinteresadamente a la investigación y a la docencia, formando discípulos que hoy día engrandecen no sólo a la UNAM, sino a otras instituciones educativas y gubernamentales. En muchos rubros podemos decir que hubo avances considerables, por ejemplo, “...se pusieron en práctica nuevas técnicas quirúrgicas y se fortalecieron los estudios de química, matemáticas y física. Médicos, juristas, economistas, filósofos, ingenieros, dieron aportes considerables" (Mayer, 2007).

Cabe acotar que la trascendencia que el exilio español dio a la ciencia mexicana, latinoamericana y al mundo es encomiable. En el caso de la mexicana se ha propagado por doquier y ha echado raíces muy profundas. No se podría entender la actividad científica actual sin este marco. Prueba de ello, es que la UNAM, institución educativa de vanguardia, y donde se realiza y produce la mayor parte de la investigación de punta que realiza el país, ha sido distinguida con el Premio Príncipe de Asturias en el área de Comunicación y Humanidades 2009. 
Sin lugar a dudas, es una distinción que reconoce la labor de la UNAM y de todos aquellos actores que han estado involucrados en ella. Ricardo Senabre Sempere, presidente del jurado, externo que "la UNAM ha sido, a lo largo de cien años, el modelo académico de muchas generaciones de estudiantes de diversos países y ha nutrido el ámbito Iberoamericano de valiosos intelectuales y científicos" agregando para el caso que nos ocupa que: "En esta casa de estudios, acogió con generosidad a ilustres personalidades del exilio español de la posguerra y ha impulsado poderosas corrientes de pensamiento humanístico, liberal y democrático en América." (Gaceta UNAM, 2009)

Para finalizar, hay que considerar, como dice Dosse (2007) en La marcha de las ideas, que "las revistas, que son uno de los soportes esenciales del campo intelectual, pueden ser consideradas como una estructura elemental de sociabilidad, espacios muy valiosos para analizar la evolución de las ideas en tanto que lugares de fermentación intelectual y de relaciones afectivas".

\section{Notas}

(1) Recopilación de frases de Matin Luther King [en línea]. Dirección URL: http://www.proverbia.net/ citasautor.asp?autor=608 [consulta: 31 de mayo de 2009]

(2) El Comité de No Intervención o Comité de Londres fue creado por Gran Bretaña y Francia a una semana de iniciada la Guerra Civil Española, con el objetivo de cumplir el Pacto de No Intervención y evitar la internacionalización del conflicto. Al poco tiempo, Alemania e Italia intervienen en el conflicto español, firmado por ambos el 8 de agosto de 1936, apoyando con hombres, armas y aviones a los nacionalistas. Ante esta flagrante violación del derecho internacional, Francia y Gran Bretaña ratifican el Pacto y niegan la intervención extranjera en el conflicto, finalmente fueron 27 países europeos los que se adhirieron al Pacto. Al respecto los diplomáticos mexicanos denunciaron la intervención y culpan al Comité de parcialidad en el conflicto. De aquellos pronunciamientos, sobresale el de Isidro Fabela en el seno de la Liga de Naciones (Fabela, 1994).

(3) Sería en el foro de la Sociedad de Naciones, donde México expresaría su negativa a las políticas imperialistas; al condenar la invasión japonesa de Manchuria, la invasión italiana de Etiopía y, más tarde, la invasión alemana y su consecuencia, la anexión de Austri.

(4) Conferencia magistral en conmemoración de los 70 años de la fundación de la Casa de España en México de la doctora Clara E. Lida. Fundación de la Casa de España. México: Colegio de México, 17:30 hrs, 1 de octubre 2008.
(5) Este grupo sobresale por su enorme trayectoria en España. Tenemos, por ejemplo, a Luis Recaséns Fiches, especialista en filosofía del derecho, profesor en la Universidad de Madrid y vicepresidente del Instituto Internacional de Filosofía del Derecho; José Gaos, filósofo discípulo de José Ortega y Gasset, rector de la Universidad de Madrid; Enrique Díez-Canedo, poeta y crítico literario, miembro de la Academia de la Lengua, director de la Escuela Central de Idiomas, ministro en Uruguay y embajador en Argentina; Agustín Millares Carlo, catedrático de paleografía, diplomática y latín medieval en la Universidad Central de Madrid, colaborador en el Centro de Estudios Históricos y director del Archivo-Biblioteca del Ayuntamiento de Madrid. Entre los científicos: Gonzalo R. Labora, psiquiatra, especializado en histopatología del sistema nervioso, presidente de la Academia Médico-Quirúrgica de Madrid y de la Academia Nacional de Medicina, presidente del Consejo Superior Psiquiátrico y director de la Clínica de Psiquiatría del Hospital Provincial de Madrid; e Isaac Costero, médico oncólogo e histólogo, director del Laboratorio de Anatomía Patológica y la sección de cultivo de tejidos del Instituto del Cáncer, anatomopatólogo de la Clínica Médica del Hospital General de Madrid y catedrático de Histología y Anatomía Patológica en la Universidad de Valladolid. A todo lo anterior hay que sumar a quienes fueron arribando en distintos contingentes a partir de 1939: poetas, artistas y críticos, como León Felipe, José Moreno Villa, Benjamín Jarnés, Juan José Domenchina y Adolfo Salazar. Y también a científicos, filósofos, sociólogos e historiadores como José Giral, Jaime Pi Suñer, Manuel Rivas Cherif, María Zambrano, José Medina Echavarría, Pedro Bosch Gimpera y muchos otros, haciendo un total de 325 intelectuales (Lida, 2003).

\section{Referencias}

Badran, Adnan (1995). Mensaje del profesor Adnan Badran. // Publicaciones científicas en América Latina = Scientific publications in Latin America. México : ICSU; UNESCO; UNAM; FCE; Academia de la Investigación Científica, A.C. (1995) 19

Cetto, Ana María (1995) Mensaje inaugural. // Publicaciones científicas en América Latina $=$ Scientific publications in Latin America . México : ICSU; UNESCO; UNAM; FCE; Academia de la Investigación Científica, A.C. (1995) 2930.

Corral Jorda Rose, Manuel; Díaz de Guereñu, James Valender; [et. al.] (1999). Los refugiados Españoles y la cultura mexicana. // Actas de las segundas jornadas celebradas en El Colegio de México en noviembre de 1996, México: El Colegio de México, 1999. 516.

Fabela, Isidro (2009). Biblioteca Isidro Fabela. Cartas al presidente Cárdenas. // La Política internacional del presidente Cárdenas. Volumen IV, Editado por el Instituto Mexiquense de Cultura- El Colegio Mexiquense- Centro Cultural Isidro Fabela-Banco de México, México, 1994.

Gaceta UNAM (2009). Órgano Informativo de la Universidad Nacional Autónoma de México. México: UNAM (2009) 4166. 6 .

Dosse, François (2007). Marcha de las ideas. Historia de los intelectuales, historia intelectual. trad., de Rafael F. 
Tomás. Valencia: Universidad de Valencia (2007). 5152.

Larralde, C.; Huitron,C (1977). La necesidad de publicar en México el trabajo científico // Naturaleza. 8 (1977) 251.

Llera Esteban, Luis de (2005). Filosofía en el exilio: España redescubre América. Ediciones Encuentro, España (2005) 72.

León Portilla, Ascensión H. de (1987). El exilio español en la UNAM (Coloquio), México (1987). 21

Lida, Clara E. (2003). La España perdida que México ganó. // Letras Libres [en línea], mayo 2003. http://letraslibres.com/index.php?art=8806 (15 mayo 2009).

Maldonado, Víctor Alfonso (1982) Vías políticas y diplomáticas del exilio. // El exilio español en México, 1939-1982. México; Salvat- FCE, 1982. 40.

Mayer, Alicia, coord. (2007). Homenaje a 70 años de la Guerra civil española. México: IIH-UNAM, 2007. 7.

Meadows, A.J (1998). Communication in science. London: Butterworth, 1974. Cit por Pullinger, David.J. Economics and organisation of primary scientific publication. 1998. http://www.Imcp.jussieu.fr/icsu/Information/Proc_ 0296/pillinger.html (20 Abr.1998).

Mora, Pablo y Ángel Miquel (2008). Españoles en el periodismo mexicano siglo XIX y XX. México, 2008. 195.

Ojeda Revah, Mario (2004). México y la Guerra Civil Española. España: Turner Publicaciones, 2004. 119- 120.

Ordóñez Alonso, María Magdalena. Los científicos del exilio español en México: un perfil. http://clio.rediris.es/ clionet/articulos/cientificos.htm (21 de mayo de 2009).

Pla Brugat, Dolores (1999a). Refugiados Españoles en México. // James Valender, Rose Corral, Juan Manuel, Díaz de Guereñu [et. al.], Op. cit. p. 426.

Pla Brugat, Dolores (1999b). Els exiliats catalans. Un estudio de la emigración republicana española en México. México, INAH-Orfeo Català de Mèxic, A.C., 1999. 175.

Pullinger, David.J (1998) Economics and organisation of primary scientific publication. 1998. http://www.Imcp. jussieu.fr/icsu/Information/Proc_0296/pillinger.html (20 Abr.1998).

Recopilación de frases de Matin Luther King [en línea]. http://www.proverbia.net/citasautor.asp?autor $=608 \quad$ (31 de mayo de 2009).

Rius, Pilar (1987) El exilio español en la UNAM (Coloquio), México (1987) 40.

Subramanyam, K (1983). Scientific and technical journals : developments and prospects. // Science and technology libraries. 40:1 (1983) 6. 